\title{
The effect of peritoneal gas drain on postoperative pain in benign gynecologic laparoscopic surgery: a double-blinded randomized controlled trial
}

This article was published in the following Dove Press journal:

International Journal of Women's Health

10 August 2016

Number of times this article has been viewed

\section{Chantip Tharanon \\ Kovit Khampitak}

Department of Obstetrics and Gynecology, Srinagarind Hospital, Khon Kaen University, Khon Kaen, Thailand
Correspondence: Kovit Khampitak

Department of Obstetrics and

Gynecology, Srinagarind Hospital, Khon

Kaen University, Mittraphap 18 Alley,

Nai Mueang, Mueang Khon Kaen District,

Khon Kaen 40002, Thailand

Tel +664366813538006

Email kovit@kku.ac.th
Objectives: To compare the effect of peritoneal gas drain on postoperative pain in benign gynecologic laparoscopic surgery and the amount of postoperative analgesic dosage.

Methods: The trial included 45 females who had undergone operations during the period December 2014 to October 2015. The patients were block randomized based on operating time ( $<2$ and $\geq 2$ hours). The intervention group ( $n=23$ ) was treated with postoperative intraperitoneal gas drain and the control group $(n=22)$ was not. The mean difference in scores for shoulder, epigastric, suprapubic, and overall pain at 6, 24, 48 hours postoperatively were statistically evaluated using mixed-effect restricted maximum likelihood regression. The differences in the analgesic drug usage between the groups were also analyzed using a Student's $t$-test. The data were divided and analyzed to two subgroups based on operating time ( $<2$ hours, $n=20$; and $\geq 2$ hours, $n=25$ ).

Results: The intervention had significantly lower overall pain than the control group, with a mean difference and 95\% confidence interval at 6, 24, and 48 hours of 2.59 (1.49-3.69), 2.23 (1.13-3.34), and 1.48 (0.3-2.58), respectively. Correspondingly, analgesic drug dosage was significantly lower in the intervention group $(3.52 \pm 1.47 \mathrm{mg}$ vs $5.72 \pm 2.43 \mathrm{mg}, P<0.001)$. The three largest mean differences in patients with operating times of $\geq 2$ hours were in overall pain, suprapubic pain at 6 hours, and shoulder pain at 24 hours at 3.27 (1.14-5.39), 3.20 (1.11-5.26), and 3.13 (1.00-5.24), respectively. These were greater than the three largest mean differences in the group with operating times of $<2$ hours, which were 2.81 (1.31-4.29), 2.63 (0.51-4.73), and 2.02 (0.68-3.36). The greatest analgesic drug requirement was in the control group with a longer operative time.

Conclusion: The use of intraperitoneal gas drain was shown to reduce overall postoperative pain in benign gynecologic laparoscopic surgery. The effects were higher in patients who had experienced longer operating times.

Keywords: laparoscopic surgery, intraperitoneal gas drain, postoperative pain, gynecology

\section{Introduction}

Operative gynecologic laparoscopy is becoming the primary approach for treatment of benign gynecologic diseases, as it is a less invasive procedure and can help shorten the length of hospitalization. ${ }^{1,2}$ Most complications occur during abdominal access or port placement, while other complications arise during abdominal insufflations, tissue dissection, and homeostasis. ${ }^{3,4}$ However, postoperative pain at the shoulder and upper abdomen has been shown to be the most common complaint in many studies. It has been hypothesized that this is due to $\mathrm{CO}_{2}$ residue, which causes stretching of the postdistended diaphragm and peritoneum after prolonged surgery. ${ }^{5-7}$ The suprapubic pain comes directly from the surgical wound, which is also affected by postoperative abdominal distension. 
Several methods have been recommended to improve postoperative pain for ambulatory procedures, including a pulmonary recruitment maneuver, ${ }^{8,9}$ intraperitoneal infusion with saline ${ }^{10}$ or analgesic drugs, ${ }^{11}$ low pressure laparoscopic surgery, ${ }^{12}$ and the prescription of different types of preoperative medicine. ${ }^{13}$

Studies have shown peritoneal gas drain to be a procedure that could potentially be used to alleviate postoperative pain. Many previous studies have reported good results from using this procedure. ${ }^{5,7,14,15}$ Recently, a systematic review mentioned that there was little evidence to support the effectiveness of intraperitoneal gas drain in reducing postoperative pain. ${ }^{16}$

This paper was, thus, designed as a block-randomized double-blinded controlled trial to determine whether or not peritoneal gas drain would be able to relieve shoulder, epigastric, suprapubic, and overall postoperative pain and also to evaluate potential differences among subgroups categorized by surgical procedure duration.

\section{Materials and methods}

This study was conducted at Srinagarind Hospital, Faculty of Medicine, Khon Kaen University from December 2014 to October 2015. Patients 18 years and older with benign gynecologic conditions for whom laparoscopic surgery was indicated were recruited. A signed consent form was obtained from all patients after they were counseled about surgical procedures, possible complications, details of the gas drain procedure, and the pain-assessment process. Routine preoperative medications administered were $1 \mathrm{~g}$ of acetaminophen orally and $50 \mathrm{mg}$ of ranitidine intravenously. Nitrous oxide, oxygen, sevoflurane, cisatracurium, and morphine were administered as anesthetic drugs during surgery. Dexamethasone (4-8 mg), ondansetron ( $8 \mathrm{mg}$ ), and diclofenac $(75 \mathrm{mg})$ were used during the recovery period to prevent postoperative nausea and vomiting.

All the operations were performed by an experienced gynecologic laparoscopist. Just before finishing the operation, the patients were assigned to either the intervention or control group using block randomization of sealed envelopes separated by operating time ( $<2$ and $\geq 2$ hours).

In the intervention group, a No 14 nasogastric tube (Zuellig Pharma, Bangkok, Thailand) was inserted $10 \mathrm{~cm}$ into the peritoneal cavity before closure of the patient's abdominal wall. In the control group, the drain tube was simply inserted under a strip of sterile gauze and there was no intraperitoneal insertion. In both groups, the external area was bandaged and connected to a sterile plastic bag after the operation.
The evaluator, a well-trained member of the nursing staff, who was blind to the procedure, was assigned to evaluate the pain level by using a visual analog scale at 6,24 , and 48 hours after the operation. After the assessment at 6 hours, a training resident was assigned to remove the drain tube. The evaluator remained blind to the process. If the patient felt pain at any time, up to $3 \mathrm{mg}$ of morphine at 4-hour intervals would be administered intravenously as needed, as described in diagram flow (Figure 1).

Preoperative data, including age, parity, body mass index, prior abdominal surgery, preoperative diagnosis, and intraoperative data, including duration of operation and estimated blood loss were recorded, as well as postoperative data, including complications, postoperative diagnosis, and length of hospital stay.

This study was approved by the Khon Kaen University Ethics Committee No HE571349.

\section{Statistical method and analysis}

The sample-size calculation was conducted using a repeated measurement calculator formula with a type I error of $1 \%$ and $80 \%$ power, resulting in each group consisting of 22 patients. A clinically significant difference would be determined if a three-point difference in visual analog scores was found. Percentage, mean, and standard deviation are described in the demographic data. Mixed-effect restricted maximum likelihood regression was used to evaluate statistical differences in the pain scores, and a Student's $t$-test was used to compare for analgesic usage. All statistical analyses were calculated using the Stata program Version 10.1 (StataCorp LP, College Station, TX, USA).

\section{Results}

Forty-five patients (intervention group, $\mathrm{N}=23$ and control group, $\mathrm{N}=22$ ) were recruited for this study. There were no statistically significant differences between the two groups in age (39.56 \pm 9.85 vs $38.86 \pm 9.76, P=0.405)$, body mass index, parity, surgical history, estimated blood loss, operating time, and pathological diagnosis (Tables 1 and 2). The pain scores of the intervention group were significantly lower at all parameters, with the exception of epigastric pain at 48 hours (mean difference $0.8,95 \%$ confidence interval [CI] -0.23 to 1.83 ). The two largest differences in mean pain scores between the groups were in the suprapubic and overall pain at 6 hours, 2.92 (95\% CI 1.86-3.98) and 2.59 (95\% CI 1.49-3.69) (Figure 2). No major postoperative 


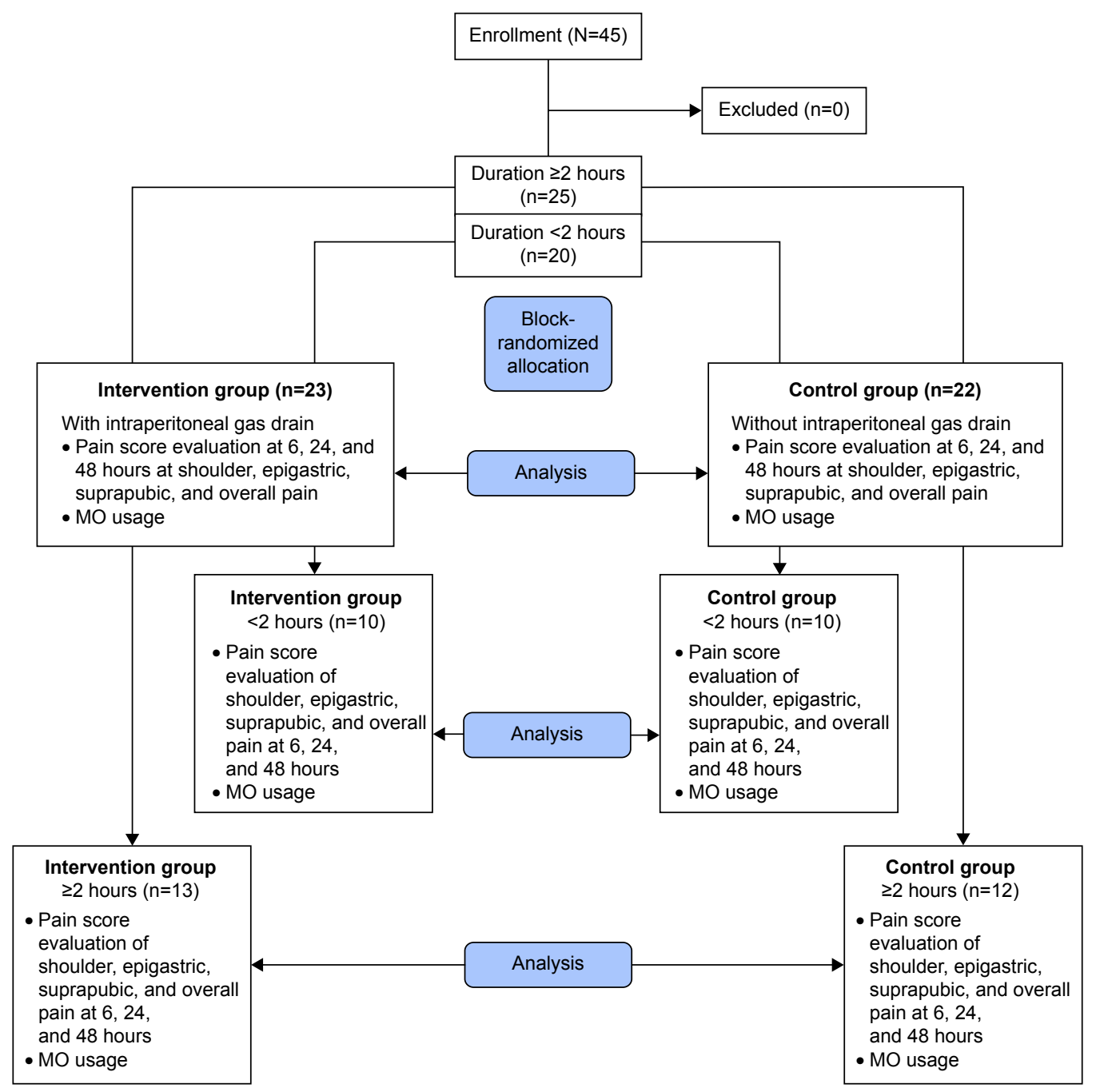

Figure I Diagram flow.

Abbreviation: MO, morphine.

complications were detected in either group, and all patients were discharged on the third day after the operation.

There were 25 patients in the operating time $\geq 2$ hours subgroup (intervention, $\mathrm{N}=13$; and control, $\mathrm{N}=12$ ), and 20 patients in the operating time $<2$ hours subgroup, (intervention and control, $\mathrm{N}=10$ ). There was no statistically significant difference in operating times between the subgroups in the intervention and the corresponding control group (Table 2).

In the $\geq 2$ hours subgroup, the intervention group showed significantly reduced overall scores at 6,24 , and 48 hours with mean differences 3.27 (95\% CI 1.14-5.39), 2.43 (95\% CI 0.72-4.14), 1.65 (95\% CI 0.39-2.90), respectively. This group also showed improvements in other parameters, as shown in Figure 3. The mean differences in shoulder pain scores at 6,24 , and 48 hours were especially better in the intervention group at 2.11 ( $95 \% \mathrm{CI}-0.30$ to 4.51$), 3.13$ (95\% CI 1.00-5.24), and 2.40 (95\% CI 0.70-4.08), respectively.

In the $<2$ hours subgroup, the intervention group showed better overall pain scores at 6,24 , and 48 hours, with lesser mean differences compared to the long operation group (Figure 3) at 1.81 (95\% CI -0.01 to -3.63$), 2.02$ (95\% CI 0.68-3.36), and 1.28 (95\% CI 0.28-2.26), respectively. Suprapubic pain was a parameter that showed significant difference in the intervention group at 6,24 , and 48 hours (Figure 3 ).

In the operating time $\geq 2$ hours subgroup, overall pain at 6 hours, suprapubic pain at 6 hours, and shoulder pain at 24 hours showed the largest mean difference at 3.27 (95\% CI 1.14-5.39), 3.20 (95\% CI 1.11-5.26), and 3.13 (95\% CI 1.00-5.24), respectively. These were higher than the three largest mean differences in operating time $<2$ hours 
Table I Preoperative and postoperative data

\begin{tabular}{|c|c|c|c|}
\hline Characteristic & $\begin{array}{l}\text { Intervention group } \\
\mathbf{N}(\%)\end{array}$ & $\begin{array}{l}\text { Control group } \\
\mathbf{N}(\%)\end{array}$ & Total \\
\hline \multicolumn{4}{|l|}{ Diagnoses } \\
\hline Endometrioma & II (40.74) & II (45.83) & $22(43.14)$ \\
\hline Leiomyoma & $9(33.33)$ & $6(25.00)$ & I5 (29.4I) \\
\hline Adenomyosis & $3(11.11)$ & I (4.16) & $4(7.8)$ \\
\hline Dermoid cyst & I (3.7) & $2(8.33)$ & $3(5.88)$ \\
\hline Simple cyst & I (3.7) & $2(8.33)$ & $3(5.88)$ \\
\hline Desired TR & $\mathrm{I}(3.7)$ & I (4.16) & $2(3.9)$ \\
\hline Endometrial polyp & I (3.7) & I (4.16) & $2(3.9)$ \\
\hline ( $>$ I diagnosis in one patient) & & & $(P=0.768)$ \\
\hline \multicolumn{4}{|l|}{ Pathological diagnoses } \\
\hline Endometriotic cyst & $8(36.36)$ & $9(40.91)$ & $17(36.17)$ \\
\hline Adenomyosis & $5(20)$ & I (4.5) & $6(12.76)$ \\
\hline Leiomyoma & $8(32)$ & $4(22.72)$ & $12(25.53)$ \\
\hline Functional cyst & 0 & $4(22.72)$ & $4(8.5 \mathrm{I})$ \\
\hline Seromucinous cystadenoma & $2(8)$ & $2(11.36)$ & $4(8.5 I)$ \\
\hline Dermoid cyst & 0 & I (4.5) & $I(2.1)$ \\
\hline Normal tubes and ovaries & I (4) & I (4.5) & $2(4.2)$ \\
\hline \multirow[t]{2}{*}{ Endometrial polyp } & I (4) & 0 & $I(2 . I)$ \\
\hline & & & $(P=0.906)$ \\
\hline \multicolumn{4}{|l|}{ Parity } \\
\hline Nulliparous & II (47.83) & $9(40.91)$ & $20(44.4)$ \\
\hline \multirow[t]{2}{*}{ Multiparous } & $12(52.17)$ & $13(59.09)$ & $25(55.56)$ \\
\hline & & & $(P=0.64 I)$ \\
\hline \multicolumn{4}{|l|}{ Body mass index } \\
\hline$<8.5$ & $2(8.7)$ & $5(22.73)$ & $7(15.56)$ \\
\hline $18.6-22.9$ & II (47.83) & $10(45.45)$ & $21(46.67)$ \\
\hline $23-24.9$ & $4(17.39)$ & I (4.55) & $5(11.11)$ \\
\hline $25-29.9$ & $4(17.39)$ & $4(18.18)$ & $8(17.78)$ \\
\hline \multirow[t]{2}{*}{$>30$} & $2(8.7)$ & $2(9.09)$ & $4(8.89)$ \\
\hline & & & $(P=0.567)$ \\
\hline \multicolumn{4}{|c|}{ History of prior abdominal surgery } \\
\hline Yes & $15(65.22)$ & 17 (77.27) & $32(71.11)$ \\
\hline \multirow[t]{2}{*}{ No } & $8(34.78)$ & $5(22.73)$ & I $3(28.89)$ \\
\hline & & & $(P=0.372)$ \\
\hline \multicolumn{4}{|l|}{ Estimated blood loss } \\
\hline$<100 \mathrm{~mL}$ & $12(52.17)$ & $15(68.18)$ & $27(55.55)$ \\
\hline $100-200 \mathrm{~mL}$ & $7(30.43)$ & $4(18.18)$ & II (24.44) \\
\hline \multirow[t]{2}{*}{$>200 \mathrm{~mL}$} & $4(17.39)$ & $3(13.63)$ & $7(15.55)$ \\
\hline & & & $(P=0.472)$ \\
\hline
\end{tabular}

Note: $P$-value of $\leq 0.05$ has a statistical significance.

Abbreviation: TR, tubal resection.

subgroup, which were 2.81 (95\% CI 1.31-4.29), 2.63 (95\%

CI 0.51-4.73), and 2.02 (95\% CI 0.68-3.36).

Correspondingly, the intervention group required lesser analgesic (morphine) dosages than the control group,
$3.52 \pm 1.47 \mathrm{mg}$ versus $5.72 \pm 2.43 \mathrm{mg}(P<0.001)$. The statistical significance was also shown in both subgroups; $3.92 \pm 1.89 \mathrm{mg}$ vs $6.50 \pm 2.81 \mathrm{mg}(P=0.007)$ in $\geq 2$ hours interval and 3.00 vs $4.80 \pm 1.55 \mathrm{mg}(P=0.002)$ in $<2$ hours interval (Table 3$)$.

Table 2 The operating time between the two groups

\begin{tabular}{llll}
\hline $\begin{array}{l}\text { Group/subgroup by } \\
\text { operating time }\end{array}$ & Operating time & & \multicolumn{1}{c}{ P-value } \\
\cline { 2 - 3 } & $\begin{array}{l}\text { Intervention group } \\
\text { Mean (minutes) } \pm \text { SD (N) }\end{array}$ & $\begin{array}{l}\text { Control group } \\
\text { Mean (minutes) } \pm \text { SD (N) }\end{array}$ \\
\hline All & $\mid 27.39 \pm 5 I .0 I(23)$ & $130.23 \pm 46.99(22)$ & 0.843 \\
$<2$ hours subgroup & $83.00 \pm 24.06(10)$ & $87.50 \pm 22.27(10)$ & 0.434 \\
$\geq 2$ hours subgroup & $\mid 61.54 \pm 37.83(13)$ & $165.83 \pm 27.70(12)$ & 0.375 \\
\hline
\end{tabular}

Note: $P$-value of $\leq 0.05$ has a statistical significance.

Abbreviations: N, number of patients; SD, standard deviation. 


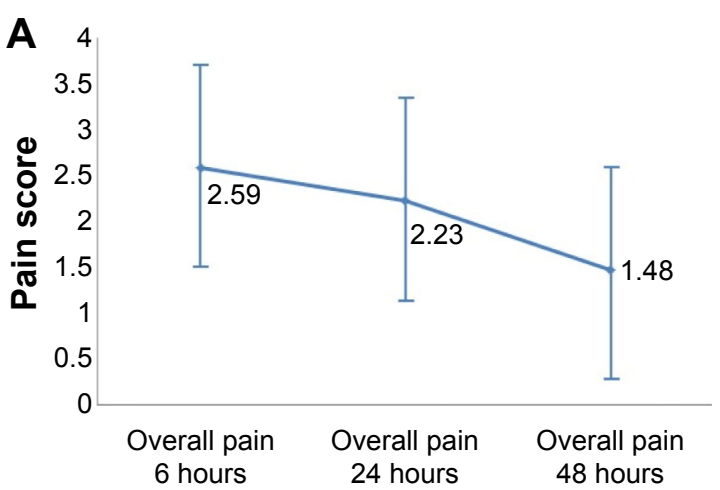

Pain location and time

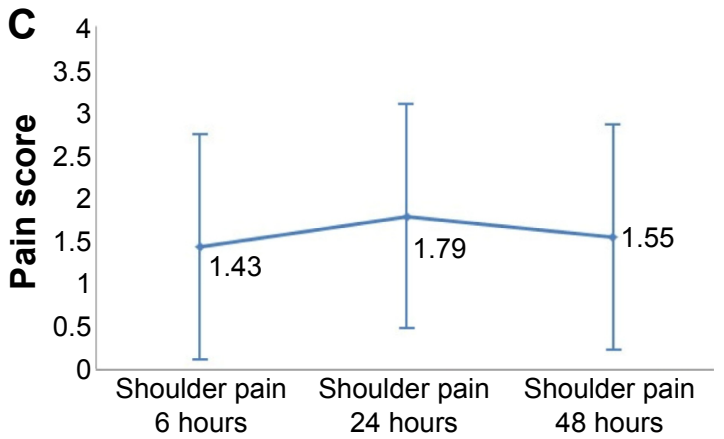

Pain location and time

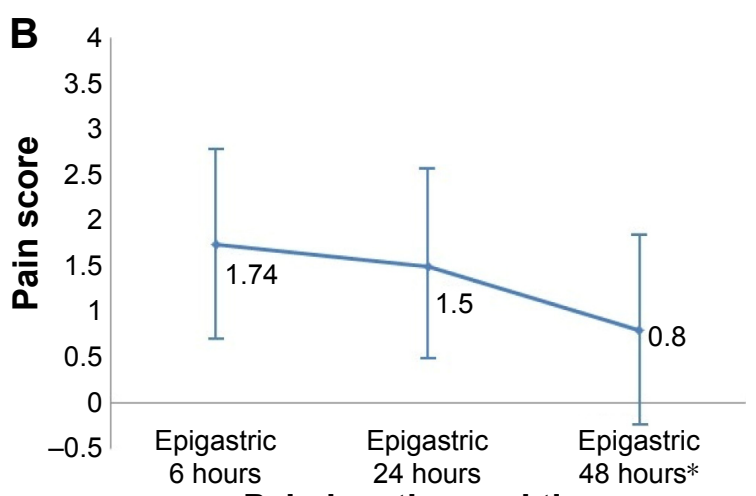

Pain location and time

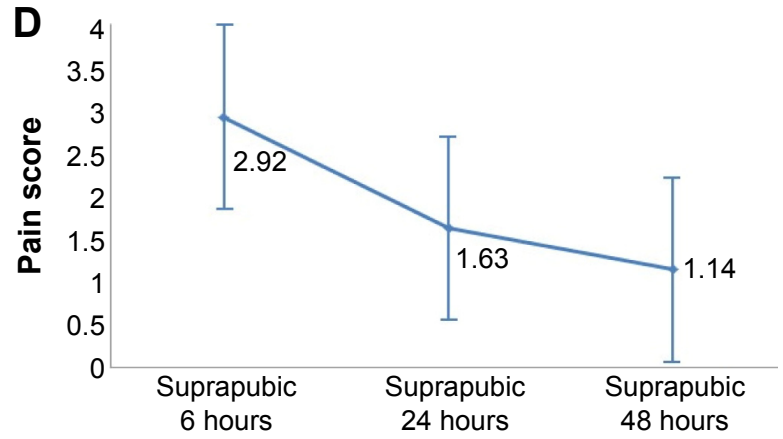

Pain location and time

Figure 2 The mean difference in pain scores of the control and intervention group and $95 \% \mathrm{Cl}$ at shoulder, epigastric, and suprapubic area including overall pain. Note: Mean difference $=$ pain score in the control group - pain score in the intervention group. (A) Overall pain evaluation, (B) epigastric pain evaluation, (C) shoulder pain evaluation, (D) suprapubic pain evaluation. *Indicates an insignificant pain difference.

Abbreviation: $\mathrm{Cl}$, confidence interval.

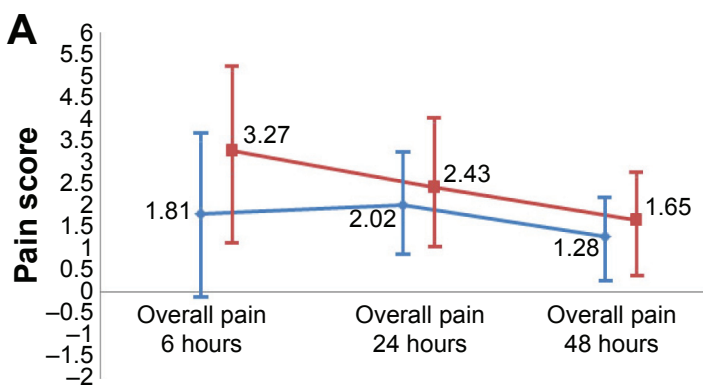

Pain location and time

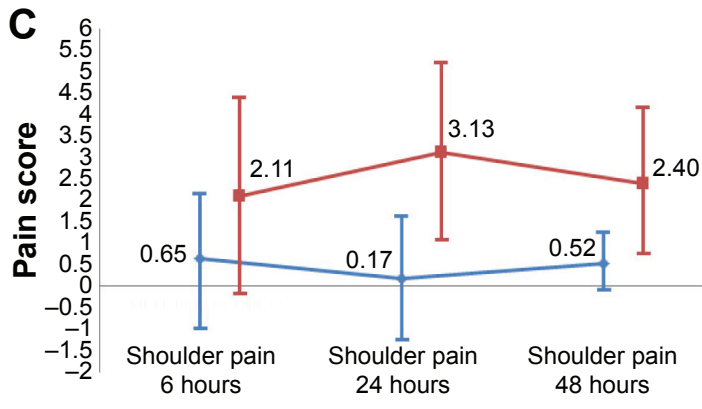

Pain location and time

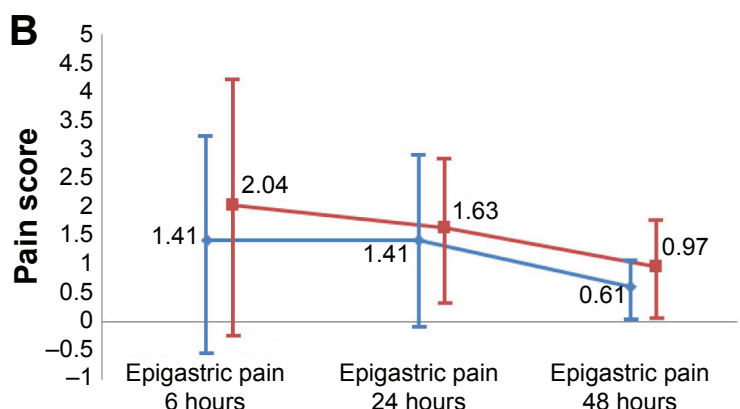

Pain location and time

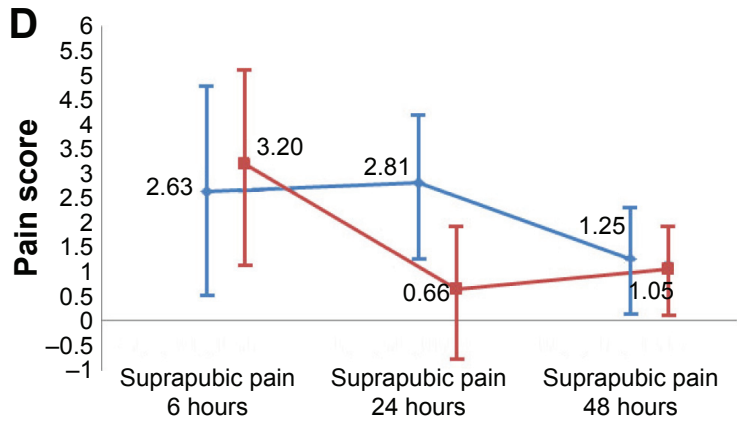

Pain location and time

Figure 3 Subgroup analysis of mean pain difference with $95 \% \mathrm{Cl}$ at shoulder, epigastric, and suprapubic area including overall pain score.

Notes: Mean difference $=$ pain score in the control group - pain score in the intervention group. $-\leftarrow=$ Subgroup analysis with the operative time of $<2$ hours. $==$ Subgroup analysis with the operative time of $\geq 2$ hours. (A) Overall pain evaluation, (B) epigastric pain evaluation, (C) shoulder pain evaluation, (D) suprapubic pain evaluation. Abbreviation: $\mathrm{Cl}$, confidence interval. 
Table 3 The amount of analgesia (morphine) required postoperatively

\begin{tabular}{llll}
\hline $\begin{array}{l}\text { Group/subgroup by } \\
\text { operating time }\end{array}$ & Amount of morphine & & P-value \\
\cline { 2 - 3 } & $\begin{array}{l}\text { Intervention group } \\
\text { Mean }(\mathbf{m g}) \pm \mathbf{S D}(\mathbf{N})\end{array}$ & $\begin{array}{l}\text { Control group } \\
\text { Mean }(\mathbf{m g}) \pm \text { SD (N) }\end{array}$ \\
\hline All & $3.52 \pm I .47(23)$ & $5.72 \pm 2.43(22)$ & 0.0006 \\
$<2$ hours subgroup & $3.00 \pm 0.0(10)$ & $4.80 \pm 1.55(10)$ & 0.002 \\
$\geq 2$ hours subgroup & $3.92 \pm 1.89(13)$ & $6.50 \pm 2.81(12)$ & 0.007 \\
\hline
\end{tabular}

Note: $P$-value of $\leq 0.05$ has a statistical significance.

Abbreviations: $\mathrm{N}$, number of patients; $\mathrm{SD}$, standard deviation.

\section{Discussion}

This paper showed that the postoperative intra-abdominal tube drain could be an effective method for improving postoperative pain at nearly all parameters. The best results were recorded when using it after laparoscopic surgery lasting $>2$ hours. The reduction in the amount of morphine required in the group with operating times $\geq 2$ hours was also greater than those with operating times $<2$ hours. The $\geq 2$ hours subgroup showed the greatest improvement with regard to shoulder pain, while in the $<2$ hours subgroup, the greatest improvement was in pelvic pain reduction.

The hypothesis was that, compared to shorter procedures, postoperative subdiaphragmatic stretching by residue $\mathrm{CO}_{2}$ after prolonged surgery ( $\geq 2$ hours) might cause more inflammation and shoulder pain, which would cause the patient to experience significant pain reduction from the gas drain. In contrast, in a shorter operation ( $<2$ hours), the suprapubic pain, which came directly from the surgical wound, was dominant compared to the shoulder pain and was also significantly reduced by the gas drain. Recently, there have been many studies of laparoscopic cholecystectomy that have yielded conflicting results. ${ }^{14,15,17}$ In these studies, pain scores in the intervention groups were higher than those in the control groups. The intervention groups also had higher rates of complications such as infection and prolonged hospitalization. These results could be explained by the duration of the drain lasting at least 24 hours, the use an active gas drain, or the type of surgery. Cholecystectomy, which takes place near the diaphragm, causes more inflammation and may result in more postoperative shoulder pain.

In a systematic review, Craciunas et $\mathrm{al}^{16}$ concluded that there was little evidence to support the use of intraperitoneal gas drain in reducing postoperative pain and suggested that future study was required to minimize the bias resulting from operating time and using the analgesic dosage as an objective measure for pain evaluation. We, thus, conducted this study according to those guidelines.

The strength of this study was that it was a block-randomized double-blinded controlled trial, which controlled for operating time between both groups. Furthermore, the operations were performed by one surgeon to control for operation bias. The main limitation of this study was the small subgroup sample size, especially in the $\geq 2$ subgroup. Further studies with larger sample sizes are recommended.

Although there are many methods to reduce postoperative pain in ambulatory laparoscopy, ${ }^{7-10,13,18}$ it is our opinion that the more complicated the laparoscopic procedure is, the longer would be the duration of surgery and hospitalization required. In addition, laparoscopic equipment will become increasingly smaller in diameter over the next decade, causing difficulty in $\mathrm{CO}_{2}$ reduction before the port suture, and then this procedure will help to prolong the duration of gas release. However, this easy and safe procedure can also be conducted in conjunction with methods mentioned above.

\section{Conclusion}

The use of intraperitoneal gas drain could significantly improve postoperative pain in benign gynecologic laparoscopic surgery. We recommend using this procedure postoperatively, especially in cases of long operating times.

\section{Acknowledgments}

We would like to thank all our colleagues, the head of the Obstetrics and Gynecology department, the Research and Academic Department, Faculty of Medicine, Khon Kaen University, the grants we have received, and the ethics committee for allowing us to conduct this research.

\section{Disclosure}

The authors report no conflicts of interest in this work.

\section{References}

1. Khampitak K, Werawatakul Y, Supokhen A, Seejorn K. A modified LAVH to reduce urinary tract injuries: 102 consecutive case-series at Srinagarind Hospital, Khon Kaen University. J Med Assoc Thai. 2012; 95(3):299-306.

2. Kongwattanakul K, Khampitak K. Comparison of laparoscopically assisted vaginal hysterectomy and abdominal hysterectomy: a randomized controlled trial. J Minim Invasive Gynecol. 2012;19(1):89-94.

3. Magrina JF. Complications of laparoscopic surgery. Clin Obstet Gynecol. 2002;45(2):469-480. 
4. Trottier DC, Martel G, Boushey RP. Complications in laparoscopic intestinal surgery: prevention and management. Minerva Chir. 2009; 64(4):339-354.

5. Jackson SA, Laurence AS, Hill JC. Does post-laparoscopy pain relate to residual carbon dioxide? Anaesthesia. 1996;51(5):485-487.

6. Sharami SH, Sharami MB, Abdollahzadeh M, Keyvan A. Randomised clinical trial of the influence of pulmonary recruitment manoeuvre on reducing shoulder pain after laparoscopy. J Obstet Gynaecol. 2010; 30(5):505-510.

7. Abbott J, Hawe J, Srivastava P, Hunter D, Garry R. Intraperitoneal gas drain to reduce pain after laparoscopy: randomized masked trial. Obstet Gynecol. 2001;98(1):97-100.

8. Pergialiotis V, Vlachos DE, Kontzoglou K, Perrea D, Vlachos GD. Pulmonary recruitment maneuver to reduce pain after laparoscopy: a meta-analysis of randomized controlled trials. Surg Endosc. 2015; 29(8):2101-2108.

9. Radosa JC, Radosa MP, Mavrova R, et al. Five minutes of extended assisted ventilation with an open umbilical trocar valve significantly reduces postoperative abdominal and shoulder pain in patients undergoing laparoscopic hysterectomy. Eur J Obstet Gynecol Reprod Biol. 2013; 171(1):122-127.

10. Straub BD, Aslani A, Enohumah K, et al. Evaluation of the effect of intra-operative intravenous fluid on post-operative pain and pulmonary function: a randomized trial comparing 10 and $30 \mathrm{ml} \mathrm{kg}(-1)$ of crystalloid. Ir J Med Sci. 2014;183(4):549-556.

11. Somaini M, Brambillasca P, Ingelmo PM, et al. Effects of peritoneal ropivacaine nebulization for pain control after laparoscopic gynecologic surgery. J Minim Invasive Gynecol. 2014;21(5):863-869.
12. Yasir M, Mehta KS, Banday VH, Aiman A, Masood I, Iqbal B. Evaluation of post operative shoulder tip pain in low pressure versus standard pressure pneumoperitoneum during laparoscopic cholecystectomy. Surgeon. 2012;10(2):71-74.

13. Valadan M, Banifatemi S, Yousefshahi F. Preoperative gabapentin to prevent postoperative shoulder pain after laparoscopic ovarian cystectomy: A randomized clinical trial. Anesth Pain Med. 2015;5(6):e31524.

14. Georgiou C, Demetriou N, Pallaris T, Theodosopoulos T, Katsouyanni K, Polymeneas $\mathrm{G}$. Is the routine use of drainage after elective laparoscopic cholecystectomy justified? A randomized trial. J Laparoendosc Adv Surg Tech A. 2011;21(2):119-123.

15. Gurusamy KS, Koti R, Davidson BR. Routine abdominal drainage versus no abdominal drainage for uncomplicated laparoscopic cholecystectomy. Cochrane Database Syst. 2013;Rev.9:CD006004.

16. Craciunas L, Stirbu L, Tsampras N. The use of a peritoneal gas drain following gynecological laparoscopy: a systematic review. Eur J Obstet Gynecol Reprod Biol. 2014;179:224-228.

17. Donatsky AM, Bjerrum F, Gogenur I. Surgical techniques to minimize shoulder pain after laparoscopic cholecystectomy. A systematic review. Surg Endosc. 2013;27(7):2275-2282.

18. Nutthachote P, Sirayapiwat P, Wisawasukmongchol W, Charuluxananan S. A randomized, double-blind, placebo-controlled trial of oral pregabalin for relief of shoulder pain after laparoscopic gynecologic surgery. J Minim Invasive Gynecol. 2014;21(4):669-673.
International Journal of Women's Health

\section{Publish your work in this journal}

The International Journal of Women's Health is an international, peerreviewed open-access journal publishing original research, reports, editorials, reviews and commentaries on all aspects of women's healthcare including gynecology, obstetrics, and breast cancer. The manuscript management system is completely online and includes

\section{Dovepress}

a very quick and fair peer-review system, which is all easy to use. Visit http://www.dovepress.com/testimonials.php to read real quotes from published authors. 